\title{
A correlation study of telomere length in peripheral blood leukocytes and kidney function with age
}

\author{
WEI-GUANG ZHANG $^{1 *}$, YONG WANG ${ }^{1 *}$, KAI HOU ${ }^{1}$, LIN-PEI JIA ${ }^{2}$, JIE MA ${ }^{2}$, DE-LONG ZHAO ${ }^{1}$, SHU-YING ZHU ${ }^{3}$, \\ XIAO-JUAN BAI ${ }^{4}$, GUANG-YAN CAI ${ }^{1}$, YAN-PING WANG ${ }^{5}$, XUE-FENG SUN $^{1}$ and XIANG-MEI CHEN ${ }^{1}$ \\ ${ }^{1}$ Department of Nephrology, Chinese People's Liberation Army General Hospital, \\ Chinese People's Liberation Army Institute of Nephrology, State Key Laboratory of Kidney Diseases, \\ National Clinical Research Center for Kidney Diseases, Beijing 100853; ${ }^{2}$ Department of Nephrology, \\ The Second Hospital of Jilin University, Changchun, Jilin 130041; ${ }^{3}$ Department of Nephrology, \\ The Second Affiliated Hospital of Nanchang Medical University, Nanchang, Jiangxi 330006; \\ ${ }^{4}$ Department of Gerontology and Geriatrics, Shengjing Hospital of China Medical University, \\ Shenyang, Liaoning 110022; ${ }^{5}$ The Medicine School of Shandong University, \\ Jinan, Shandong 250012, P.R. China
}

Received January 11, 2014; Accepted January 2, 2015

DOI: $10.3892 / \mathrm{mmr} .2015 .3292$

\begin{abstract}
The current study aimed to investigate the association between telomere length in peripheral blood leukocytes and kidney function in various age groups of a healthy population. A total of 139 healthy individuals were divided into five groups according to their age: $35-44,45-54,55-64,65-74$ and $>75$ years old. Peripheral blood leukocytes were obtained and the telomere restriction fragment (TRF) length was assayed using a digoxigenin-labeled hybridization probe in Southern blot assays. Laboratory assays of kidney function were also performed. A correlation was observed between TRF length and age $(\mathrm{r}=-0.314, \mathrm{P}<0.001)$, with the telomere length of the individuals $>75$ years group being significantly shorter than the telomere length of the 35-44, 45-54 and 55-64 years age groups $(\mathrm{P}<0.05)$. By contrast, the TRF length for males versus females did not differ for any of the age groups, while a correlation was observed between TRF length and serum levels of cystatin $\mathrm{C}(\mathrm{r}=-0.195, \mathrm{P}<0.05)$. There was also a correlation between TRF length and glomerular filtration rate $(r=-0.184$, $\mathrm{P}<0.05)$. The current study demonstrated that in this cohort,
\end{abstract}

Correspondence to: Professor Xiang-Mei Chen or Professor Xue-Feng Sun, Department of Nephrology, Chinese People's Liberation Army General Hospital, Chinese People's Liberation Army Institute of Nephrology, State Key Laboratory of Kidney Diseases, National Clinical Research Center for Kidney Diseases, 28 Fuxing Road, Beijing 100853, P.R. China

E-mail: xmchen301@126.com

E-mail: xfssun@126.com

${ }^{*}$ Contributed equally

Key words: telomere length, aging, kidney function, cystatin C leukocyte telomere length reduced with age and was correlated with serum levels of cystatin $\mathrm{C}$ and glomerular filtration rate. Therefore, TRF length is associated with kidney function and may serve as a marker of aging.

\section{Introduction}

Telomeres are highly conserved, repetitive nucleotide sequences at the ends of chromosomes in eukaryotic cells (1). Human telomeric DNA, which is comprised of tandem TTAGGG repeats, has a total length of 5-15 kilobases and does not encode a protein (2). The predominant function of telomeres is to cap the chromosome ends, thereby maintaining chromosomal stability and the integrity of gene replication by preventing chromosome degradation, fusion and recombination (3). Consequently, telomeres maintain the genetic content of chromosomes (4). Telomerase is a reverse transcriptase, which mediates the de novo synthesis of telomeric sequences at the ends of chromosomes in order to maintain telomere length (5). In adult humans, telomerase activity is only detected in germ cells, certain stem cells and peripheral lymphocytes (6). In addition, telomeres have been observed to shorten with each round of cell division (7). When telomere length shortens to a critical length (termed the Hayflick limit), it loses its ability to protect the genetic integrity of chromosomes, resulting in genetic instability and ultimately replicative senescence (8).

Telomere length shortens with age in the majority of tissues and cells, although the rate of shortening has been reported to vary between individuals (9). In addition, telomere shortening with cell division is considered an inherent mechanism of cellular senescence (10). Thus, telomere length may represent a potential marker for aging (11-14), in addition to being an accurate marker of the age of an individual.

The kidney is an organ that is known to be affected by aging (15). The incidence of chronic kidney disease (CKD) and end-stage renal disease in the elderly has been increasing 
and thus the kidney has become a focus in aging-associated studies. Although the mechanisms of aging in the kidney remain unclear, it is hypothesized that telomere shortening may be involved (16). For example, Melk et al (16) previously demonstrated that telomere shortening progresses in an age-dependent manner in human kidneys. In addition, Westhoff et al (17) confirmed that telomere shortening enhances kidney damage in animal models and this can reduce the capacity to repair the kidneys following injury.

Few studies on telomere length and kidney function in the elderly have been conducted (17). Thus, the aim of the present study was to investigate telomere length with respect to age. Specifically, Southern blotting was used to measure the telomere restriction fragment (TRF) length of peripheral blood leukocytes obtained from healthy volunteers of various ages. These data were also compared with various surrogate markers of kidney function in order to investigate the relevance of telomere length to renal function in a healthy cohort.

\section{Materials and methods}

Sample screening. In 2011, 139 healthy volunteers were selected from 673 candidate volunteers, aged 35 to 90 years, from the Han population in Beijing, China. The volunteers were not taking any medication and had not been hospitalized in the previous three years. All participants gave informed consent subsequent to a clear explanation of the potential risks of the study. The study inclusion criteria and a flow chart for the study enrollment process were previously described $(18,19)$. The current study was approved by the Ethics Committee on Human Experimentation of the Chinese People's Liberation Army General Hospital (Beijing, China) and was conducted in accordance with the Declaration of Helsinki and subsequent amendments. The volunteers that were selected were divided into five groups according to age: $35-44,45-54,55-64$, $65-74$ and $>75$ years.

Detection of indices. Various patient characteristics were recorded for each volunteer, including gender, age, height, weight, waist circumference, hip circumference and blood pressure, including systolic blood pressure, diastolic blood pressure, pulse pressure and pulse pressure index. Laboratory indicators were also assayed AU500 (Beckman Coulter, Brea, CA, USA) that included the following: Blood urea nitrogen, creatinine, uric acid, creatinine clearance rate, triglyceride, total cholesterol, low density lipoprotein, high density lipoprotein, blood and urine routine analyses, serum levels of cystatin C (CYSC) and estimated glomerular filtration rate (eGFR) was measured using the Chronic Kidney Disease Epidemiology Collaboration (CKD-EPI) formula (20).

Genomic DNA was isolated using a cell tissue genomic DNA extraction kit (Tiangen Biotech (Beijing) Co., Ltd., Beijing, China) and TRF length was measured using the Telo TTAGGG telomere length assay (Roche Diagnostics $\mathrm{GmBH}$, Mannheim, Germany). In brief, genomic DNA (1.5 mg) was digested with the restriction enzymes, RsaI and HinfI (Roche Diagnostics $\mathrm{GmBH}$ ), for $2 \mathrm{~h}$ at $37^{\circ} \mathrm{C}$. The resulting DNA fragments were separated on a $0.8 \%$ agarose gel by electrophoresis, then were subsequently denatured, neutralized, transferred to a nylon membrane (Roche Diagnostics $\mathrm{GmBH}$ ) via capillary
Table I. Characteristics of the cohort.

\begin{tabular}{lccc}
\hline Age group (years) & Male & Female & Total \\
\hline $35-44$ & 14 & 13 & 27 \\
$45-54$ & 13 & 13 & 26 \\
$55-64$ & 13 & 14 & 27 \\
$65-74$ & 15 & 16 & 31 \\
$>75$ & 14 & 14 & 28 \\
Total & 69 & 70 & 139 \\
\hline
\end{tabular}

Table II. Characteristics of the telomeric DNA samples analyzed.

\begin{tabular}{lccc}
\hline Lane & Number & Age (years) & Gender \\
\hline 3 & H44 & 71 & Male \\
4 & H50 & 63 & Male \\
5 & H54 & 77 & Male \\
6 & H58 & 57 & Female \\
7 & H62 & 68 & Female \\
8 & H67 & 62 & Female \\
9 & H70 & 60 & Female \\
10 & H74 & 79 & Female \\
\hline
\end{tabular}

transfer at $15-20^{\circ} \mathrm{C}$ using a $20 \mathrm{X}$ saline-sodium citrate transfer buffer (Roche Diagnostics GmBH) and cross-linked with UV light (UVP, Inc., Upland, CA, USA). Blotted DNA fragments were then incubated with a telomeric probe [digoxigenin (DIG) 3'-end labeled 5'-(CCCTAA)3; Roche Diagnostics GmBH] at $42^{\circ} \mathrm{C}$ for $3 \mathrm{~h}$, followed by incubation with a DIG-specific polyclonal sheep antibody (Roche Diagnostics GmBH) covalently coupled to alkaline phosphatase. Binding sites of the telomere probe were visualized using a highly sensitive chemiluminescence substrate that metabolizes alkaline phosphatase. TRF lengths were then compared with molecular weight markers (Roche Diagnostics GmBH) (2) and mean TRF lengths were estimated using Quantity One 1-D analysis software (Bio-Rad Laboratories, Inc., Hercules, CA, USA) (2).

Statistical analysis. Statistically significant differences were identified using a linear regression model. Data were expressed as the mean \pm standard deviation and $\mathrm{P}<0.05$ was considered to indicate a statistically significant difference. All statistical calculations were performed using SPSS software, version 17.0 (SPSS, Inc., Chicago, IL, USA).

\section{Results}

General characteristics of the study subjects. A total of 139 healthy subjects were enrolled (69 males and 70 females) and divided into five groups according to age: 35-44, 45-54, 55-64, 65-74 and >75 years (Table I). Peripheral blood leukocytes were collected from each subject and genomic DNA was isolated. 
Table III. Mean TRF length determined for each age group.

\begin{tabular}{lccc}
\hline $\begin{array}{l}\text { Age group } \\
\text { (years) }\end{array}$ & Number of samples & $\begin{array}{l}\text { Mean TRF } \\
\text { (kilobases) }\end{array}$ & P-value \\
\hline $35-44$ & 27 & $6.924^{\mathrm{a}}$ & 0.001 \\
$45-54$ & 26 & $6.514^{\mathrm{a}}$ & 0.028 \\
$55-64$ & 27 & $6.464^{\mathrm{a}}$ & 0.036 \\
$65-74$ & 31 & 5.944 & 0.406 \\
$>75$ & 28 & 5.626 & 1 \\
\hline
\end{tabular}

${ }^{\mathrm{a}} \mathrm{P}<0.05$ vs. $>75$ years age group. TRF, telomere restriction fragment.

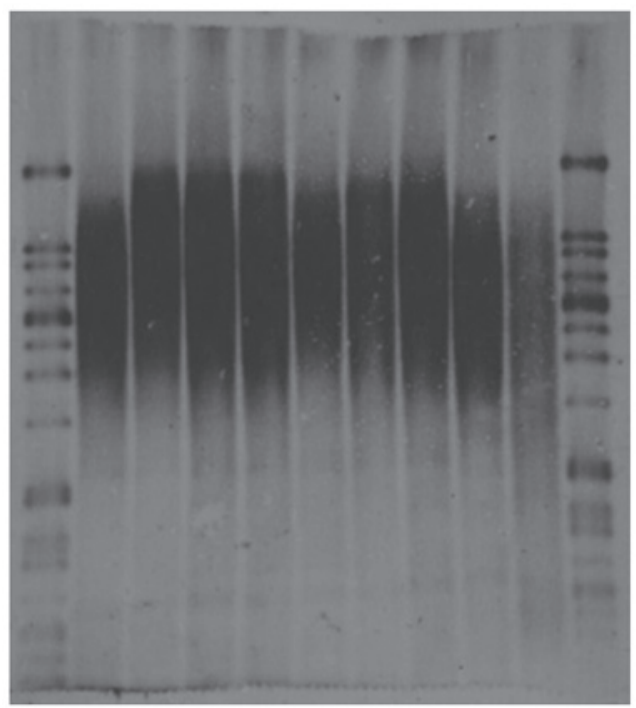

Figure 1. Southern blotting was conducted to detect the results of the telomere restriction fragment assays performed. A representative Southern blot is presented. Lane 1-11 (from left to right): Lane 1 and lane 11 include markers, and lane 2 is the control. Lanes 3-10 include the subset of samples that were analyzed for length of telomeric DNA.

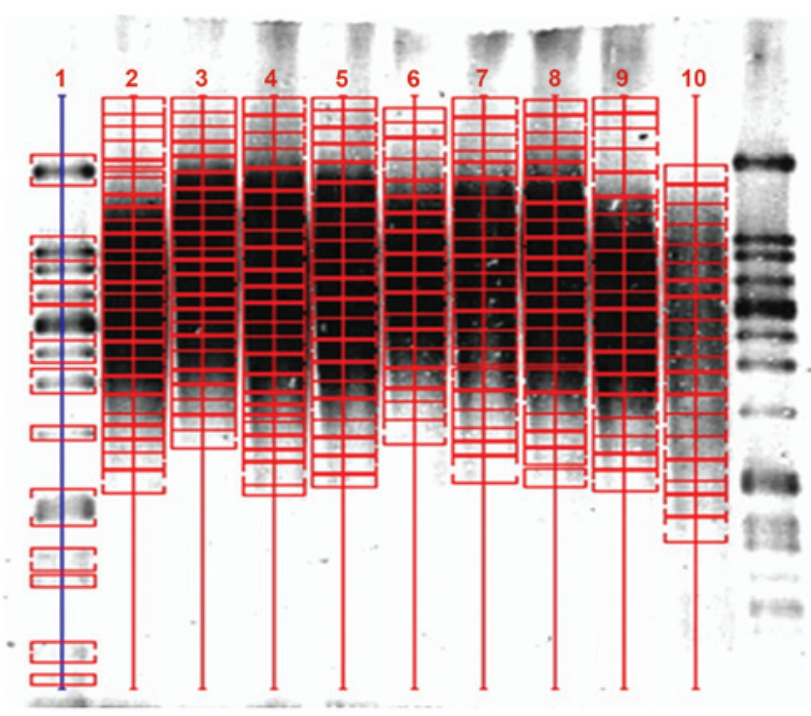

Figure 2. A representative analysis of Southern blotting data using Quantity One software to obtain mean telomere restriction fragment length. Lane 1-11 (from left to right): Lane 1 and lane 11 include markers and lane 2 is the control. Lanes 3-10 include the subset of samples that were analyzed for length of telomeric DNA.

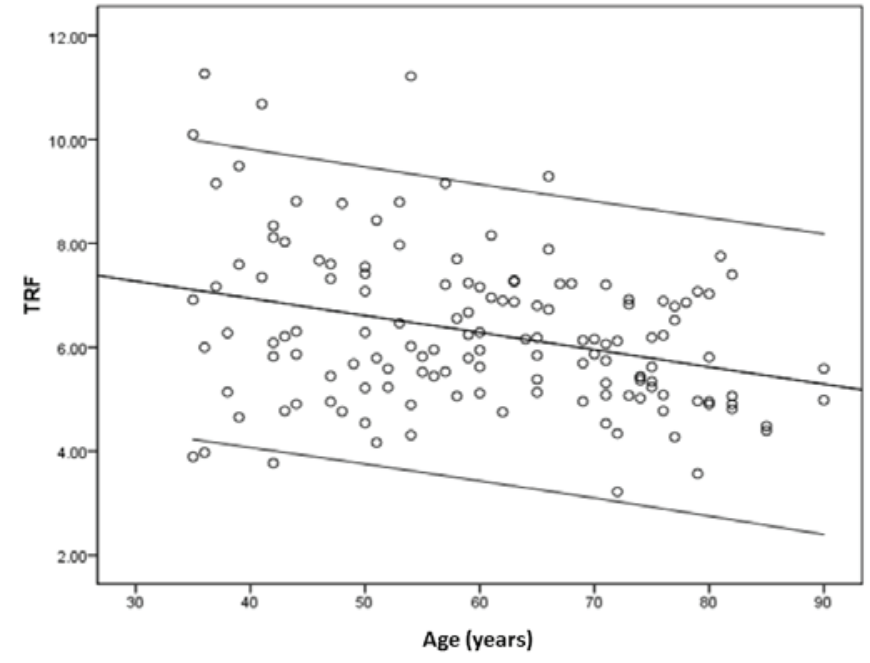

Figure 3. Scatter plot of mean TRF length and subject age. A scatter plot of TRF lengths and age, a correlation was observed $(r=-0.314, \mathrm{P}<0.05)$. TRF, telomere restriction fragment.

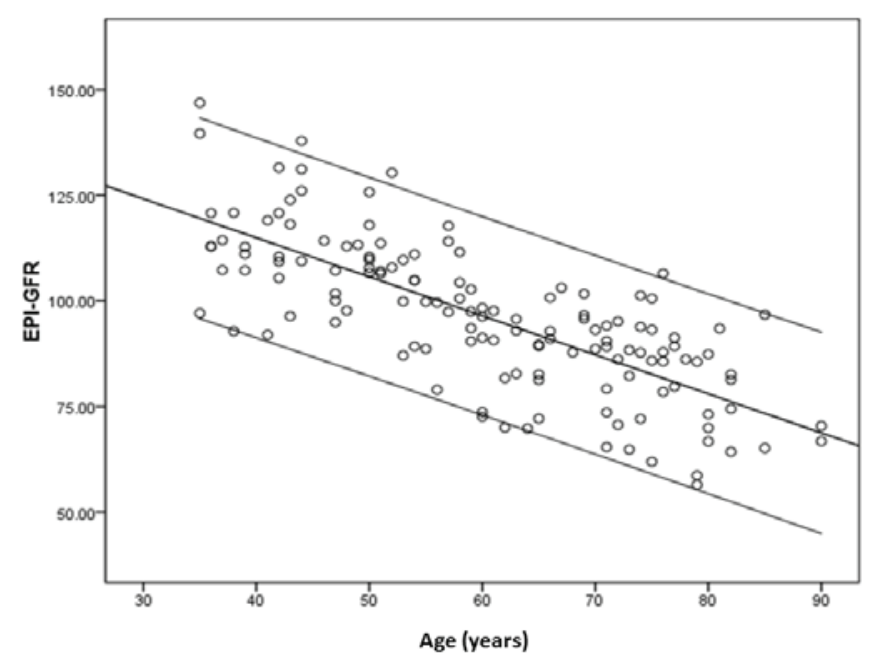

Figure 4. Scatter plot of subject age and eGFR CKD-EPI values. A scatter plot of age and eGFR CKD-EPI, a correlation was observed ( $\mathrm{r}=-0.746, \mathrm{P}<0.001)$. eGFR CKD-EPI, estimated glomerular filtration rate by the Chronic Kidney Disease Epidemiology Collaboration formula.

Detection of TRF lengths. Using a Telo TTAGGG telomere length assay, TRF lengths for each sample were analyzed using Southern blotting (Fig. 1, Table II). Mean TRF lengths were then examined using Quantity One software (Fig. 2). TRF length for the $>75$ years age group was observed to be significantly shorter than the 35-44, 45-54 and 55-64 years age groups $(\mathrm{P}<0.05$; Table III). In addition, a scatter plot of TRF lengths and age (Fig. 3) generated a regression equation of: $\mathrm{Y}=-0.033 \mathrm{X}+8.269$ (Y, mean TRF length; $\mathrm{X}$, age) and a correlation coefficient of -0.314 . Thus, the correlation between TRF length and age was demonstrated to be significant $(\mathrm{P}<0.001)$. To investigate gender-specific alterations in telomere length in human peripheral blood leukocytes, TRF lengths for males versus females were compared for all five age groups. However, no significant difference in TRF lengths with regard to gender was observed in any of the age groups analyzed (P>0.05; Table IV). 
Table IV. Mean TRF lengths according to gender ( \pm SD).

\begin{tabular}{|c|c|c|c|c|c|c|}
\hline \multirow[b]{2}{*}{ Age group (years) } & \multicolumn{2}{|c|}{ Number } & \multicolumn{2}{|c|}{ Mean \pm SD TRF $(k b)$} & \multirow[b]{2}{*}{$\mathrm{t}$-value } & \multirow[b]{2}{*}{ P-value } \\
\hline & Males & Females & Male & Female & & \\
\hline $35-44$ & 14 & 13 & $6.96 \pm 2.37$ & $6.87 \pm 1.84$ & 0.106 & 0.916 \\
\hline $45-54$ & 13 & 13 & $6.59 \pm 1.47$ & $6.43 \pm 1.97$ & 0.239 & 0.813 \\
\hline $55-64$ & 13 & 14 & $6.49 \pm 1.16$ & $6.42 \pm 0.91$ & 0.173 & 0.864 \\
\hline $65-74$ & 15 & 16 & $5.89 \pm 0.85$ & $5.99 \pm 1.43$ & -0.257 & 0.799 \\
\hline$>75$ & 14 & 14 & $5.79 \pm 1.08$ & $5.46 \pm 1.08$ & 0.818 & 0.421 \\
\hline
\end{tabular}

$\mathrm{SD}$, standard deviation; TRF, telomere restriction fragment; kb, kilobase.

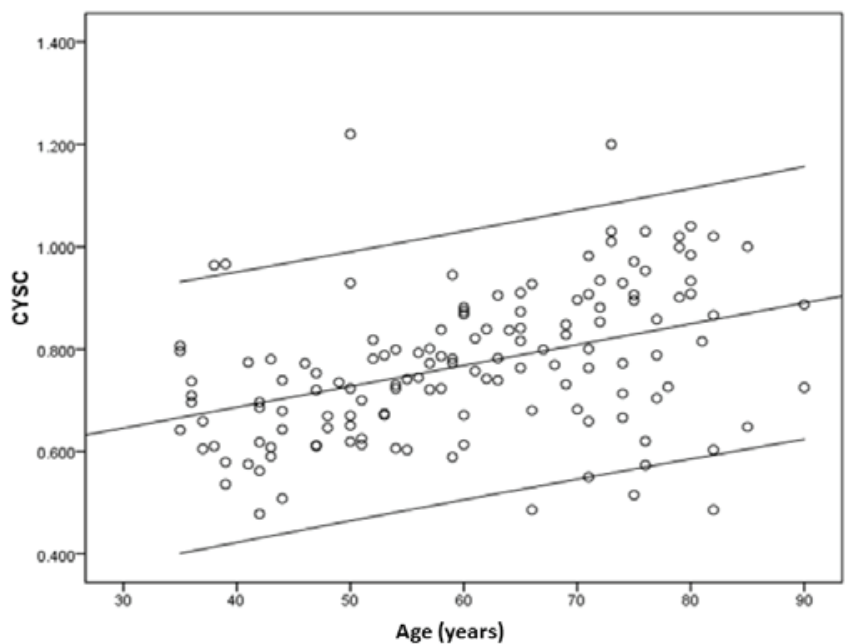

Figure 5. Scatter plot of subject age and CYSC. A scatter plot illustrating the correlation observed between age and CYSC $(r=0.405, \mathrm{P}<0.001)$. CYSC, serum levels of cystatin C.

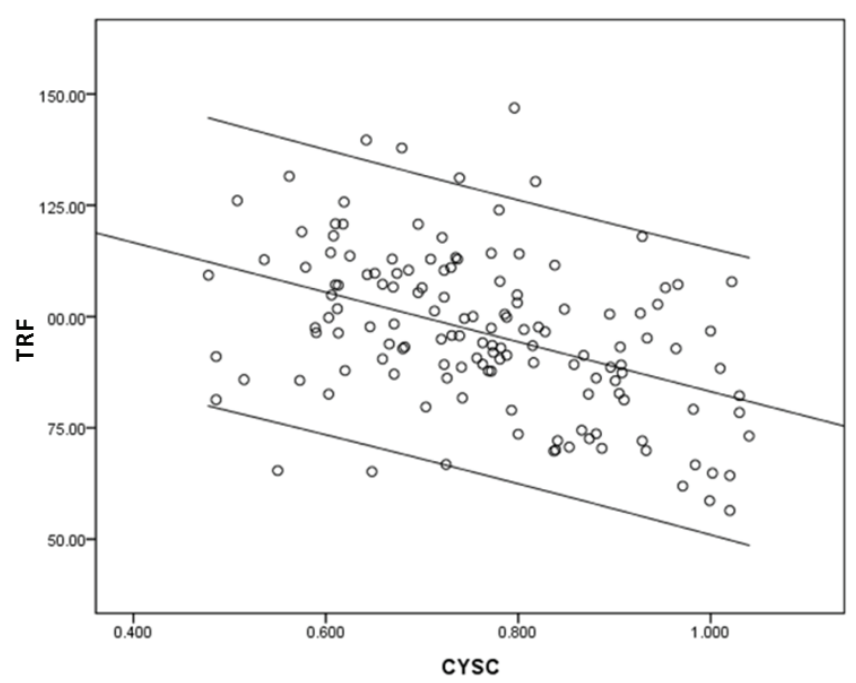

Figure 6. Scatter plot of TRF lengths and CYSC. A scatter plot illustrating the correlation observed between TRF length and CYSC $(r=-0.195, P=0.02)$. TRF, telomere restriction fragment; CYSC, serum levels of cystatin C.

Correlation between TRF lengths and kidney function indices. In order to investigate the relevance of telomere length and alterations in renal function, eGFR CKD-EPI was calculated using serum creatinine levels in order to estimate GFR (20). It was observed that eGFR reduced with age (Fig. 4) and was associated with a correlation coefficient of $-0.746(\mathrm{P}<0.001)$. However, when the correlation between eGFR and TRF length of peripheral blood leukocytes was examined, a Spearman correlation coefficient of $-0.184(\mathrm{P}=0.03)$ was observed, indicating that an association exists between eGFR and TRF.

Serum levels of CYSC also increased with age ( $r=0.405$, $\mathrm{P}<0.001$; Fig. 5) and appeared to correlate with TRF length $(\mathrm{r}=-0.195, \mathrm{P}=0.02)$ (Fig. 6).

\section{Discussion}

Aging is a degenerative process that involves the gradual degradation of biological systems. The accumulation of irreversible degenerative alterations can result in an increased vulnerability to disease and eventual mortality. Telomeres are highly conserved regions of DNA that maintain the stability and integrity of chromosomes and therefore, the stability of a genome. In order to achieve this, telomeres act as a buffer during the process of cell division by preventing the shortening of chromosomes and a loss of genetic material (4). A previous study demonstrated that when telomeres become sufficiently shortened, this buffer function is lost (21) and the cell recognizes that cell division must be stopped. As a result, telomere length has the potential to act as a biological clock, thereby regulating the aging process (22).

In a study by Aubert et al (1), telomere length in peripheral blood lymphocytes of 400 healthy individuals was observed to gradually shorten with increasing age. In addition, rates of shortening were increased in infancy and old age. Valdes et al (23) also analyzed TRF length for peripheral blood leukocytes obtained from a general population. These results indicated that there was a significant negative correlation between TRF length and increasing age. In the present study, TRF was assessed in 139 healthy individuals and telomere length was demonstrated to shorten with increasing age. The correlation between TRF length and age observed $(r=-0.314)$ was consistent with a review of 124 cross-sectional studies of telomere length and age, which indicated that telomere length was negatively correlated with age independent of absolute telomere length $(\mathrm{r}=-0.338)$ or relative telomere length $(r=-0.295)(24)$. 
It has been reported that females have longer telomeres and life expectancies than males (25). However, in the present study, TRF was not observed to differ between males and females, and these results are consistent with the analysis of an Amish population by Cawthon et al (26). Therefore, further studies are required to determine whether there is a correlation between telomere length and gender.

The kidney is an organ affected by aging and the histological alterations associated with this process include: Progressive regression of renal mass associated with glomerulosclerosis, tubular atrophy, interstitial fibrosis and fibrous thickening of the arterial intima $(27,28)$. In addition, these functional alterations are associated with increased renal vascular resistance, reduced renal blood flow and a progressive decline in GFR. In a previous study, GFR was observed to be stable until the age of 30-40 years old and subsequently declined linearly at an average rate of $\sim 8 \mathrm{ml} / \mathrm{min} /$ decade (29).

CYSC is an endogenous indicator of renal function, which has recently been demonstrated to provide improved sensitivity, specificity and accuracy compared with creatinine (30-32). CYSC is an endogenous cysteine protease inhibitor that is constitutively expressed and persistently secreted in all nucleated cells. Since CYSC is produced at a constant rate, freely filtered by the glomerulus and is almost entirely reabsorbed and disassimilated in the proximal tubule (33), it is only excreted through the kidneys. Thus, it is recommended as a marker of GFR. In healthy individuals, the concentrations of CYSC have been observed to vary with age, thus have been suggested as a biomarker of healthy aging (20). For example, when Finney et al (34) examined 401 British elderly individuals (65-101 years old), it was observed that CYSC increased with age. In addition, an analysis of 309 healthy blood donors demonstrated that concentrations of CYSC were higher in donors that were older than 50 years of age (35). Consistently, an additional study observed that in urine samples from 338 healthy subjects (age, 0-95 years), the levels of CYSC were varied according to age (36). In the present study, CYSC was also observed to increase with age $(\mathrm{r}=0.405, \mathrm{P}<0.001)$, although $\mathrm{CYSC}$ was only observed to be associated with TRF length $(r=-0.195, P=0.02)$. Similarly, a cardiovascular health study of 419 individuals $>65$ years old from the United States demonstrated a correlation between human TRF length and CYSC (37). The results of the present study are consistent with these observations. Therefore, human peripheral blood leukocyte telomere length is suggested to serve as a marker of kidney function. In order to verify this, large-scale, multi-center prospective studies are required. In particular, if a correlation between CYSC and telomere length were to be confirmed, early alterations in renal function may aid in the identification of individuals at risk for age-associated kidney disease.

In the present study, eGFR CKD-EPI was calculated using serum creatinine levels in order to estimate GFR. eGFR values were observed to reduce with age and these results are consistent with those of previous studies $(38,39)$. When eGFR and TRF length in peripheral blood leukocytes were compared, a correlation was observed $(\mathrm{r}=-0.184, \mathrm{P}<0.05)$. This result is consistent with previous study in Holland of 866 patients with heart failure, in which an association between telomere length and GFR ( $\mathrm{r}=0.123, \mathrm{P}<0.001)$ was identified (40). By contrast, a study by Melk et al (16) demonstrated that the association between telomere length and GFR was not relevant. It should be considered that the number of samples analyzed in the present study was limited. Therefore, the exact association between telomere DNA length and GFR requires further investigation.

The association between telomere length and kidney function in aging remains to be confirmed; however, the current study suggests that telomere length serves a role in the aging and function of kidneys. Therefore, further investigation of the association between telomere length, aging and renal function are required in order to improve preserve renal function and prevent associated morbidity and mortality. It is hypothesized that progress in this field may result in reduced healthcare costs for aging populations.

\section{Acknowledgements}

The authors would like to thank those who participated in the current study. The study was supported by the National Basic Research Program of China (2103CB530800) and the National Key Technology R\&D Program (2011BAI10B00) and the Natural Science Foundation of China (81270819).

\section{References}

1. Aubert $\mathrm{G}$ and Lansdorp PM: Telomeres and aging. Physiol Rev 88: 557-579, 2008.

2. Tsuji A, Ishiko A, Takasaki $\mathrm{T}$ and Ikeda $\mathrm{N}$ : Estimating age of humans based on telomere shortening. Forensic Sci Int 126: 197-199, 2002.

3. Schuldt A: Telomeres: Damage response cut short. Nat Rev Mol Cell Biol 13: 137, 2012.

4. Wong JM and Collins K: Telomere maintenance and disease. Lancet 362: 983-988, 2003.

5. Lingner J, Hughes TR, Shevchenko A, et al: Reverse transcriptase motifs in the catalytic subunit of telomerase. Science 276: 561-567, 1997.

6. Hiyama E and Hiyama K: Telomere and telomerase in stem cells. Br J Cancer 96: 1020-1024, 2007.

7. Allsopp RC, Chang E, Kashefi-Aazam M, et al: Telomere shortening is associated with cell division in vitro and in vivo. Exp Cell Res 220: 194-200, 1995.

8. Pickett HA and Reddel RR: The role of telomere trimming in normal telomere length dynamics. Cell Cycle 11: 1309-1315, 2012.

9. Djojosubroto MW, Choi YS, Lee HW and Rudolph KL: Telomeres and telomerase in aging, regeneration and cancer. Mol Cells 15: 164-175, 2003.

10. Blackburn EH: Telomere states and cell fates. Nature 408: 53-56, 2000.

11. Baker GT III and Sprott RL: Biomarkers of aging. Exp Gerontol 23: 223-239, 1988.

12. Mooradian AD: Biomarkers of aging: do we know what to look for? J Gerontol 45: B183-B186, 1990.

13. Arking R (ed): The Biology of Aging: Observations and Principles. 3rd edition. Oxford University Press, New York, 2006.

14. Vasto S, Scapagnini G, Bulati M, et al: Biomarkes of aging. Front Biosci (Schol Ed) 2: 392-402, 2010.

15. Zhou XJ, Rakheja D, Yu X, et al: The aging kidney. Kidney Int 74: 710-720, 2008.

16. Melk A, Ramassar V, Helms LM, et al: Telomere shortening in kidneys with age. J Am Soc Nephrol 11: 444-453, 2000.

17. Westhoff JH, Schildhorn C, Jacobi C, et al: Telomere shortening reduces regenerative capacity after acute kidney injury. J Am Soc Nephrol 21: 327-336, 2010.

18. Zhang WG, Bai XJ and Chen XM: SIRT1 variants are associated with aging in a healthy Han Chinese population. Clin Chim Acta 411: 1679-1683, 2010.

19. Bai X, Han L, Liu Q, et al: Evaluation of biological aging process-a population-based study of healthy people in China. Gerontology 56: 129-140, 2010.

20. Levey AS, Stevens LA, Schmid $\mathrm{CH}$, et al: A new equation to estimate glomerular filtration rate. Ann Intern Med 150: 604-612, 2009. 
21. Olovnikov AM: A theory of marginotomy: the incomplete copying of template margin in enzymic synthesis of polynucleotides and biological significance of the phenomenon. J Theor Biol 41: 181-190, 1973.

22. Shawi $M$ and Autexier C: Telomerase, senescence and ageing. Mech Ageing Dev 129: 3-10, 2008.

23. Valdes A, Andrew T, Gardner J, et al: Obesity, cigarette smoking, and telomere length in women. Lancet 366: 662-664, 2005.

24. Müezzinler A, Zaineddin AK and Brenner H: A systematic review of leukocyte telomere length and age in adults. Ageing Res Rev 12: 509-519, 2013.

25. Tarry-Adkins JL, Chen JH, Smith NS, Jones RH, Cherif H and Ozanne SE: Poor maternal nutrition followed by accelerated postnatal growth leads to telomere shortening and increased markers of cell senescence in rat islets. FASEB J 23: 1521-1528, 2009.

26. Cawthon RM, Smith KR, O'Brien E, Sivatchenko A and Kerber RA: Association between telomere length in blood and mortality in people aged 60 years or older. Lancet 361: 393-395, 2003.

27. Zhou XJ, Saxena R, Liu Z, Vaziri ND and Silva FG: Renal senescence in 2008: progress and challenges. Int Urol Nephrol 40: 823-839, 2008

28. Silva FG: The aging kidney: a review - part I. Int Urol Nephrol 37: $185-205,2005$

29. Morrissey PE and Yango AF: Renal transplantation: older recipients and donors. Clin Geriatr Med 22: 687-707, 2006.

30. Ozer BA, Dursun B, Baykal A, Gultekin M and Suleymanlar G: Can cystatin $\mathrm{C}$ be a better marker for the early detection of renal damage in primary hypertensive patients? Ren Fail 27: 247-253, 2005.

31. Cepeda F, Fernández E, Pobes A and Baños L: Utility of cystatin-C in hospitalized patients. Comparing with different methods of assessing renal function. Nefrologia 27: 168-174, 2007 (In Spanish).
32. Hojs R, Bevc S, Ekart R, Gorenjak M and Puklavec L: Serum cystatin C-based equation compared to serum creatinine-based equations for estimation of glomerular filtration rate in patients with chronic kidney disease. Clin Nephrol 70: 10-17, 2008.

33. Jacobsson B, Lignelid $\mathrm{H}$ and Bergerheim US: Transthyretin and cystatin $\mathrm{C}$ are catabolized in proximal tubular epithelial cells and the proteins are not useful as markers for renal cell carcinomas. Histopathology 26: 559-564, 1995.

34. Finney H, Bates CJ and Price CP: Plasma cystatin C determinations in a healthy elderly population. Arch Gerontol Geriatr 29: 75-94, 1999.

35. Finney H, Newman DJ and Price CP: Adult reference ranges for serum cystatin $\mathrm{C}$, creatinine and predicted creatinine clearance. Ann Clin Biochem 37: 49-59, 2000.

36. Pennemans V, Rigo JM, Faes C, Reynders C, Penders J and Swennen Q: Establishment of reference values for novel urinary biomarkers for renal damage in the healthy population: are age and gender an issue? Clin Chem Lab Med 51: 1795-1802, 2013.

37. Sanders JL, Fitzpatrick AL, Boudreau RM, et al: Leukocyte telomere length is associated with noninvasively measured age-related disease: the Cardiovascular Health Study. J Gerontol A Biol Sci Med Sci 67: 409-416, 2012.

38. Sun X, Chen Y, Chen X, et al: Change of glomerular filtration rate in healthy adults with aging. Nephrology (Carlton) 14: 506-513, 2009.

39. Lindeman RD, Tobin J and Shock NW: Longitudinal studies on the rate of decline in renal function with age. J Am Geriatr Soc 33: 278-285, 1985.

40. Wong LS, van der Harst P, de Boer RA, et al: Renal dysfunction is associated with shorter telomere length in heart failure. Clin Res Cardiol 98: 629-634, 2009. 